\title{
Osteopathy for Endometriosis and Chronic Pelvic Pain - a Pilot Study
}

\section{Osteopathie bei Endometriose und chronischen Unterbauchschmerzen - eine Pilotstudie}

Authors

Affiliations
M. Sillem ${ }^{1}$, I. Juhasz-Böss ${ }^{2}$, I. Klausmeier ${ }^{3}$, S. Mechsner ${ }^{4}$, F. Siedentopf ${ }^{5}$, E. Solomayer ${ }^{2}$

1 Praxisklinik am Rosengarten, Mannheim, Germany

2 Frauenklinik Homburg, Uniklinikum Saarland, Homburg/Saar, Germany

${ }^{3}$ DC Physiotherapie, Universitätsmedizin Mannheim, Mannheim, Germany

${ }^{4}$ Gynäkologie, Campus Benjamin Franklin, Charité, Berlin, Germany

${ }^{5}$ Klinik für Gynäkologie und Geburtshilfe, Martin-Luther-Krankenhaus, Berlin, Germany

\section{Key words \\ - endometriosis \\ osteopathy \\ - chronic pelvic pain \\ Schlüsselwörter \\ - Endometriose \\ - Osteopathie \\ - chronische Unterbauch- schmerzen}

Deutsche Version unter: http://dx.doi.org/ $10.1055 / \mathrm{s}-0042-111010$

\section{received 29.3.2016 \\ revised 15.5.2016 \\ accepted 22.6.2016}

Bibliography

Dol http://dx.doi.org/

10.1055/s-0042-111010

Geburtsh Frauenheilk 2016; 76 :

960-963 @ Georg Thieme

Verlag KG Stuttgart - New York . ISSN 0016-5751

\section{Correspondence}

\section{Dr. Martin Sillem,}

Priv.-Doz. Dr. med.

Praxisklinik am Rosengarten

Augustaanlage 7-11

68165 Mannheim

Germany

martin.sillem@t-online.de

\section{Abstract \\ $\nabla$}

Introduction: Pelvic pain is a common problem in gynaecological practice. It is often unclear whether definite causality exists between reported symptoms and objective clinical findings of the female genital tract, and medical or operative treatments do not always achieve long-term resolution of symptoms.

Methods: This pilot study investigated 28 patients (age 20-65, median 36.5 years) from a gynaecology practice whose only clinical finding was painful pelvic floor muscle tightness. Following standardised gynaecological and physiotherapist examination, all patients received osteopathic treatment. Pain had been present for a median of 3 years (range 1 month to 20 years). 14 patients had previously confirmed endometriosis. Treatment success was evaluated on consultation with patients in person or in writing.

Results: 22 of the 28 participants completed the treatment according to plan. Overall, 17 reported symptom improvement, while 10 of the $14 \mathrm{pa}-$ tients with endometriosis did.

Conclusion: Osteopathy is well received by women with painful pelvic floor muscle tightness and appears to be an effective treatment option.

\section{Introduction \\ $\nabla$}

No accurate epidemiological data on the incidence of chronic pelvic pain in women, an ill-defined term, have been published to date. In a review of the international literature, Latthe et al. [1] state a prevalence of $2-24 \%$ for chronic, non-

\section{Zusammenfassung \\ $\nabla$}

Einleitung: Unterbauchschmerzen sind ein häufiges Problem in der gynäkologischen Praxis. Der Kausalzusammenhang zwischen objektivem Befund am inneren Genitale und den geklagten Beschwerden ist oft nicht eindeutig und nicht immer führen medikamentöse oder operative Therapien zu einer dauerhaften Beschwerdefreiheit.

Methodik: Im Rahmen einer Pilotstudie wurden 28 Patientinnen (Alter 20-65, Median 36,5 Jahre) einer gynäkologischen Praxis untersucht. Als einziger klinisch auffälliger Befund fanden sich schmerzhafte Verspannungen des muskulären Beckenbodens. Nach einer standardisierten gynäkologischen und physiotherapeutischen Untersuchung wurden diese Patientinnen osteopathisch behandelt. Die Schmerzen bestanden seit 3 Jahren (Median, Bereich 1 Monat bis 20 Jahre). Bei 14 Patientinnen war in der Vorgeschichte eine Endometriose gesichert worden. Der Behandlungserfolg wurde durch Befragung evaluiert.

Ergebnisse: 22 von 28 Patientinnen schlossen die Therapie planmäßig ab. 17 Patientinnen gaben an, die Beschwerden hätten sich durch die Behandlung gebessert. Bei den Patientinnen mit Endometriose gaben 10 von 14 eine Besserung an. Schlussfolgerung: Osteopathie wird von Frauen mit muskulären Verspannungen des Beckenbodens gut angenommen und scheint eine wirksame Therapie darzustellen.

cyclical pelvic pain; estimates for the USA and Germany are between 7 and 15\% [2-4].

In gynaecological practice the question often arises as to whether clinical, imaging or endoscopic findings adequately explain reported pain symptoms [5]. For example, endometriosis has been found in at least $20 \%$ of women undergoing laparoscopic tubal ligation. In Germany the me- 


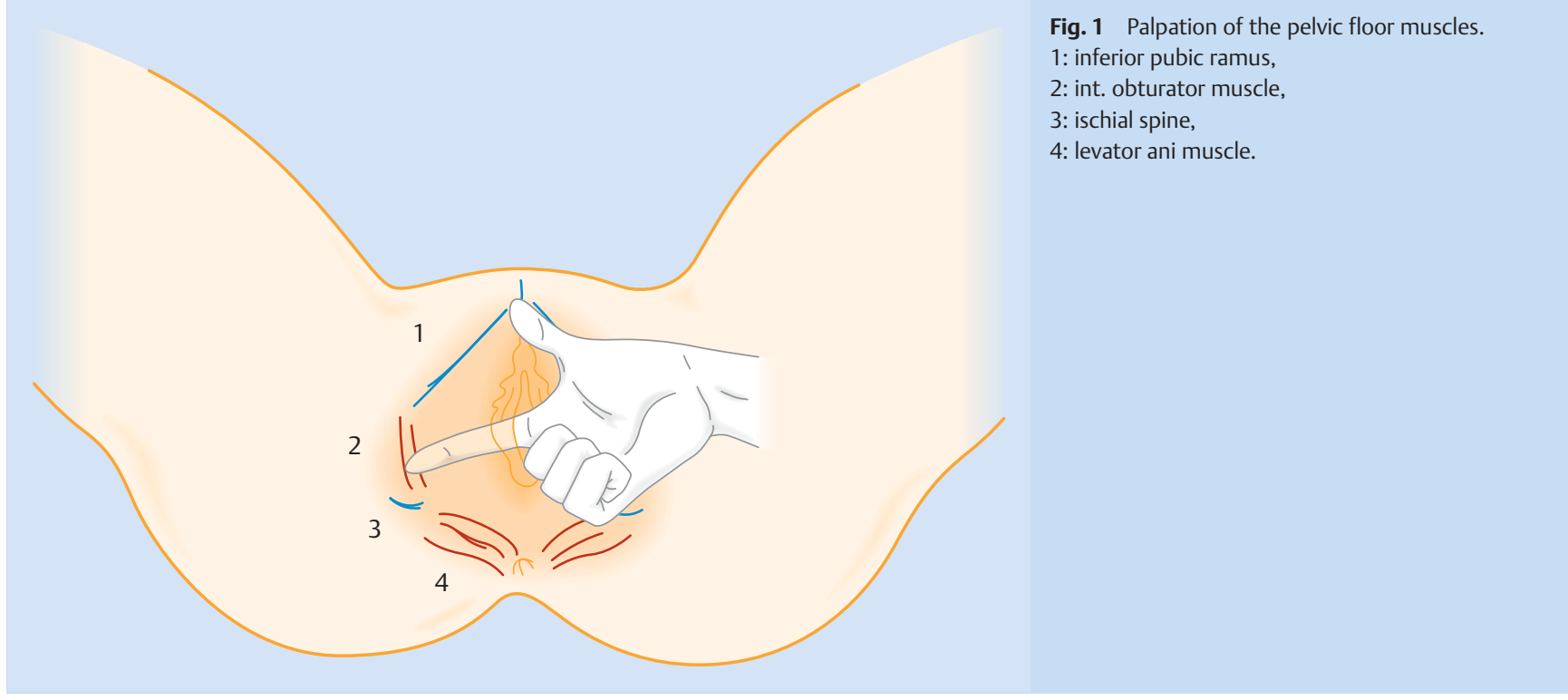

dian interval from endometriosis diagnosis to onset of symptoms is 10.4 years [6]. This highlights the unsatisfactory situation these patients find themselves in, however this particular study sheds no light on whether available treatments are effective.

Women with chronic pelvic pain very often have painful pelvic floor muscle tightness [7] - a rare finding in healthy, symptomfree women [8]. Significant comorbidity with musculoskeletal diseases exists, a fact that is not widely acknowledged [9].

The term "osteopathy" describes a school of diagnosis and treatment developed by the American Andrew Taylor Still. Its central focus is on musculo-fascial structures and their influence on somatic symptoms. Three forms of practice have evolved: parietal osteopathy, visceral osteopathy and craniosacral therapy. Evidence exists to different degrees - in descending order - supporting the efficacy of each of the three subdivisions of osteopathy [10].

Osteopathy describes causality between numerous symptoms and diseases due to the fascial connections between the musculoskeletal system and the internal organs. Thus, inflammation of internal organs can cause musculoskeletal symptoms and vice versa (e.g. injuries of the axial skeleton can cause abdominal symptoms). Also, functional limitation at one skeletal level may cause symptoms at a different level. These interconnections are described as "lesion chains" [11].

This pilot study investigates the efficacy of osteopathic diagnosis and treatment for women with chronic pelvic pain and painful pelvic floor muscle tightness not related to the menstrual cycle.

\section{Materials and Methods}

\section{Patients}

28 women presented to our clinic at a certified endometriosis centre with chronic lower abdominal symptoms not clearly related to the menstrual cycle. 14 of these patients had previously confirmed endometriosis. In the control group of 14 patients without known endometriosis, 7 had previous abdominal surgery for other reasons (uterine fibroids, appendicectomy, cholecystectomy, Crohn's disease, ileus during infancy); specific, endoscopic exclusion of endometriosis was however not carried out since dysmenorrhea and infertility did not feature as prominent symptoms in this group ( Table $\mathbf{1}$ ).

Group allocation was on the basis of clinical history.

\section{Gynaecological examination}

Apart from the gynaecological history, particular note was taken of symptoms, diseases and injuries of the axial skeleton. All patients underwent a standard gynaecological examination by the same investigator (M. Sillem). Additional transvaginal digital palpation of the levator ani and internal obturator muscles was performed. Bony landmarks were the inferior pubic ramus and the ischial spine ( Fig. 1). A diagnosis of painful muscle tightness was made if there was tenderness on careful palpation. All patients also underwent transvaginal ultrasound examination. All patients were offered further investigation with (repeat) laparoscopy and/or medication as alternatives to osteopathic treatment.

\section{Study inclusion}

Only patients with painful tightness of the pelvic floor musculature were included in the study. Patients with concurrent pathological findings on clinical or ultrasound examination of the genital tract (cysts, fibroids) were treated accordingly and excluded from the study.

After selection, patients were presented to a physiotherapist with osteopathy training (I. Klausmeier). A clinical history was taken, with particular attention to musculoskeletal and abdominal symptoms/injuries, followed by a systematic examination (sacroiliac joint mobility, tenderness on abdominal palpation, posture, range of motion of the hips, spine).

\section{Osteopathic treatment}

A standardised approach was used starting with release of musculoskeletal blocks, particularly of the sacroiliac joints. Depending on clinical findings, this was followed by mobilisation of the diaphragm and abdominal organs using standard techniques. The pelvic floor was released using the so-called "grand manoeuvre" (movement of the abdominal organ compartment in a cranial direction). The treatment was concluded in many cases with mobilisation of the temporomandibular joints and cervical spine. 
Table 1 Summary of differences between patients with and without endometriosis.

\begin{tabular}{|llll} 
& Number & $\begin{array}{l}\text { Duration of symptoms in years } \\
\text { median (range) }\end{array}$ & $\begin{array}{l}\text { Number of laparoscopies/-tomies } \\
\text { median (range) }\end{array}$ \\
\hline Known endometriosis & 14 & $8(2-20)$ & $2(1-4)$ \\
\hline No known endometriosis & 14 & $0.1(0.1-5)$ & $0.5(0-3)$
\end{tabular}

Table 2 Treatment success as a function of previously diagnosed endometriosis.

\begin{tabular}{|llllllll} 
& Number & Improved & Repeat prescription & Did not improve & Therapy stopped & No follow-up \\
\hline Endometriosis & 14 & 10 & 5 & 2 & 1 & 2 \\
\hline No known endometriosis & 14 & 7 & 3 & 1 & 5 & 6 \\
\hline
\end{tabular}

Table 3 Treatment success as a function of known/previous musculoskeletal diseases/injuries.

\begin{tabular}{|llllllll} 
& Number & Improved & Repeat prescription & Did not improve & Therapy stopped & No follow-up \\
\hline Positive history & 11 & 5 & 2 & 1 & 2 & 5 \\
\hline Negative history & 17 & 12 & 0 & 2 & 0 & 2 \\
\hline
\end{tabular}

\section{Table 4 Comorbidity.}

\begin{tabular}{llll} 
& Number & Musculoskeletal & \multicolumn{1}{c}{ Psychosomatic $^{{ }^{*}}$} \\
Known endometriosis & 14 & 6 & 5 \\
\hline No known endometriosis & 14 & 5 & 3 \\
\hline
\end{tabular}

${ }^{1}$ Previous history of musculoskeletal disease/injury.

Each patient was prescribed 6 treatment sessions, of which a median of 6 were carried out (range 1-24), usually at weekly intervals.

\section{Evaluation}

A few weeks after treatment completion, patients were questioned in person or in writing on their satisfaction with the treatment.

\section{Results}

$\nabla$

\section{Clinical history}

Duration of symptoms ranged from a few weeks up to 20 years, median 3 years. 21 patients had previously had an abdominal operation: 9 had one previous laparoscopy or laparotomy, 8 patients had 2 , one patient 3 , and 3 patients 4 previous laparoscopies and/or laparotomies.

10 of the patients with endometriosis were taking or had previously taken hormonal treatment, in 6 cases dienogest mono. Four of these patients had had no improvement of symptoms.

11 patients reported injuries or diseases of the axial skeleton/ musculoskeletal system or specifically the lower limbs (3 motor vehicle accidents, 3 sacral injuries, 2 knee injuries, and 1 each for scoliosis, pelvic ring fracture and multiple fractures). Six patients had had psychotherapy, which had been recommended for a further two patients.

\section{Osteopathic treatment}

Patients underwent a median of 6 (range 1-24) osteopathic treatment sessions each lasting 30 minutes. 22 patients com- pleted treatment as planned with only two patients discontinuing after a single session. The median of repeat prescriptions was 2.5 (range 0 to 5). The group of 14 patients with endometriosis differed significantly from the rest of the participants as follows: longer duration of symptoms, more previous operations and both better treatment compliance and outcome ( $\bullet$ Tables 2 to 4 ). In contrast there was no difference in comorbidity between the groups. Five out of 11 cases with musculoskeletal diseases/injuries benefitted from osteopathic treatment, whereas all 5 patients with endometriosis and psychiatric comorbidity did.

Three patients without any symptom improvement after osteopathic treatment re-presented to the gynaecology clinic: One, with a history of previous endometriosis, required surgery for a newly diagnosed ovarian endometrioma; two were receiving and had benefitted from psychotherapy.

\section{Discussion} the treatment of endometriosis and pelvic pain on the basis of muscular tightness.

There is little scientific data on the use of osteopathy in general, and available data often has limited validity. In a PubMed search only one study on the described techniques for the treatment of endometriosis was found. Daraï and colleagues [12] used osteopathy to treat 20 patients with deep infiltrating endometriosis, of whom one third had already been operated and $70 \%$ were receiving medication. Physical wellbeing improved in $80 \%$ of patients and $60 \%$ had improved psychological wellbeing. In a Cochrane Review, however, Proctor et al. [13] concluded that spinal 
manipulation (a parietal osteopathic technique) was of no benefit for dysmenorrhea.

Chronic pain arising from areas bordering the internal genital organs includes backache/low-back pain and urinary tract pain syndromes. A systematic review of osteopathy for lower back pain found numerous studies of which only two were high-quality: One showed an effect no better than placebo, the other found similar effects for osteopathy, conventional physiotherapy and physical/sporting activity [14]. However, a prospective, doubleblind, randomised trial of 455 patients, which was published soon thereafter and included a control arm receiving a sham treatment, showed a highly significant positive effect [15]. A systematic review of osteopathy in women with lower urinary tract symptoms also showed a statistically significant positive effect [16].

Endometriosis is a disease prone to recurrence, with recurrence rates estimated at 20 and 50\% respectively two and five years after primary treatment [17]. However, it has also been found in at least $20 \%$ of women undergoing routine tubal ligation for family planning [18]. This means that other causes of pain and alternative treatment approaches must be considered, especially when proven effective treatments fail. Endometriosis patients in our study were burdened by long histories of suffering and multiple operations. These women were more likely to benefit from osteopathy and had better compliance than women without known endometriosis.

A history of injury or disease of the musculoskeletal system with consequent tension of the pelvic floor musculature was common among our study patients. Psychopathological comorbidity was considerable, as shown by the number of women being recommended or already receiving psychotherapy.

Osteopathy was well received as a treatment option by participants in our study and proved effective in this heterogenous group with multiple previous treatments. On the one hand, the validity of this pilot study is limited by small population size and the lack of systematic follow-up, on the other hand all patients were examined and treated in a standardised fashion by the same two investigators.

\section{Conclusion}

We consider osteopathy to be a valuable additional treatment method as part of the multimodal approach to the treatment of endometriosis and chronic pelvic pain.

\section{Conflict of Interest}

\section{$\nabla$}

The authors declare that no conflict of interest exists.

\section{References}

1 Latthe P, Latthe M, Say L et al. WHO systematic review of prevalence of chronic pelvic pain: a neglected reproductive health morbidity. BMC Public Health 2006; 6: 177

2 Jamieson DJ, Steege JF. The prevalence of dysmenorrhea, dyspareunia, pelvic pain, and irritable bowel syndrome in primary care practices. Obstet Gynecol 1996; 87: 55-58

3 Mathias SD, Kuppermann M, Liberman RF et al. Chronic pelvic pain: prevalence, health-related quality of life, and economic correlates. Obstet Gynecol 1996; 87: 321-327

4 Beutel ME, Weidner K, Brähler E. [Chronic pelvic pain of women and its co-morbidity]. Geburtsh Frauenheilk 2005; 65: 61-67

5 AWMF, Hrsg. Chronischer Unterbauchschmerz der Frau. AWMF-Leitlinie Reg. Nr. 016/001. 2009. Online: http://www.awmf.org/leitlinien/ detail/11/016-001.html; last access: 25.07.2016

6 Hudelist G, Fritzer N, Thomas A et al. Diagnostic delay for endometriosis in Austria and Germany: causes and possible consequences. Hum Reprod 2012; 27: 3412-3416

7 Montenegro ML, Mateus-Vasconcelos EC, Rosa e Silva JC et al. Importance of pelvic muscle tenderness evaluation in women with chronic pelvic pain. Pain Med 2010; 11: 224-228

8 Kavvadias T, Pelikan S, Roth P et al. Pelvic floor muscle tenderness in asymptomatic, nulliparous women: topographical distribution and reliability of a visual analogue scale. Int Urogynecol J 2013; 24: 281-286

9 Ostensen $M$, Schei B. Sociodemographic characteristics and gynecological disease in 40-42 year old women reporting musculoskeletal disease. Scand J Rheumatol 1997; 26: 426-434

10 Bundesärztekammer. Wissenschaftliche Bewertung osteopathischer Verfahren. Dtsch Arztebl 2009; 106: A-2325/B-1997/C-1941

11 Langer W, Hebgen E, Hrsg. Lehrbuch Osteopathie. Stuttgart: Haug; 2012

12 Daraï C, Deboute O, Zacharopoulou Cet al. Impact of osteopathic manipulative therapy on quality of life of patients with deep infiltrating endometriosis with colorectal involvement: results of a pilot study. Eur J Obstet Gynecol Reprod Biol 2015; 188: 70-73

13 Proctor ML, Hing W, Johnson TC et al. Spinal manipulation for primary and secondary dysmenorrhoea. Cochrane Database Syst Rev 2006; (3): CD002119

14 Orrock PJ, Myers SP. Osteopathic intervention in chronic non-specific low back pain: a systematic review. BMC Musculoskelet Disord 2013; 14: 129

15 Licciardone JC, Kearns CM, Minotti DE. Outcomes of osteopathic manual treatment for chronic low back pain according to baseline pain severity: results from the OSTEOPATHIC Trial. Man Ther 2013; 18: 533-540

16 Franke $H$, Hoesele $K$. Osteopathic manipulative treatment (OMT) for lower urinary tract symptoms (LUTS) in women. J Bodyw Mov Ther 2013; 17: 11-18

17 Guo SW. Recurrence of endometriosis and its control. Hum Reprod Update 2009; 15: 441-461

18 Moen $\mathrm{MH}$. Endometriosis in women at interval sterilization. Acta Obstet Gynecol Scand 1987; 66: 451-454 